\title{
คPPlanned Parenthood
}

\section{By the Numbers}

These numbers show why Planned Parenthood is one of the nation's leading providers of high-quality, affordable health care for women, men and young people, and the nation's largest provider of sex education.

- Number of years Planned Parenthood has provided women, men, and young people with the education, information, and services needed to make responsible choices about sex and reproduction: 101

- Number of women, men, and young people worldwide provided with sexual and reproductive health care, education, and outreach by Planned Parenthood in a single year: $\mathbf{5 , 4 0 0 , 0 0 0}$

- Number of these clients served by Planned Parenthood affiliate health centers in the U.S.: $\mathbf{2}, \mathbf{4 0 0 , 0 0 0}$

- Number of these clients served by Planned Parenthood affiliate educational programs and outreach: 1,500,000

- Number of these clients served by PPFA-supported partners in 12 developing countries: $\mathbf{1 , 5 0 0 , 0 0 0}$

- Number of Planned Parenthood affiliates: 56 (with a presence in all 50 states and the District of Columbia)

- Number of Planned Parenthood affiliate health centers: more than $\mathbf{6 0 0}$

- Percentage of Planned Parenthood health care patients

- age 20 and older: 85

- with incomes at or below 150 percent of the federal poverty level: nearly 75

- who receive services to prevent unintended pregnancy: 77

- Estimated number of unintended pregnancies averted by Planned Parenthood contraceptive services in a single year: 400,000

- Percentage of all Planned Parenthood health services that are contraceptive services: 28

- Visits to www.plannedparenthood.org in a single year: $\mathbf{7 3}$ million

- Number of Planned Parenthood activists, supporters, and donors: 11,000,000 